\title{
Ultrasound-Assisted Vacuum Impregnation as a Strategy for the Management of Potato By-Products
}

\author{
Dominik Mierzwa ${ }^{1, *(1)}$, Justyna Szadzińska ${ }^{1}$, Elżbieta Radziejewska-Kubzdela ${ }^{2}$ and Róża Biegańska-Marecik ${ }^{2}$ (]) \\ 1 Institute of Technology and Chemical Engineering, Department of Process Engineering, Poznań University \\ of Technology, Ul. Berdychowo 4, 60-965 Poznań, Poland; justyna.szadzinska@put.poznan.pl \\ 2 Department of Food Technology of Plant Origin, Poznan University of Life Sciences, Ul. Wojska Polskiego 31, \\ 60-624 Poznań, Poland; elarad@up.poznan.pl (E.R.-K.); roza.marecik@up.poznan.pl (R.B.-M.) \\ * Correspondence: dominik.mierzwa@put.poznan.pl; Tel.: +48-61-665-3969
}

check for updates

Citation: Mierzwa, D.; Szadzińska, J.; Radziejewska-Kubzdela, E.;

Biegańska-Marecik, R.

Ultrasound-Assisted Vacuum

Impregnation as a Strategy for the

Management of Potato By-Products.

Sustainability 2021, 13, 3437. https://

doi.org/10.3390/su13063437

Academic Editors: Malgorzata

Nowacka, Urszula Tylewicz, Artur Wiktor and Patricio R. Santagapita

Received: 25 February 2021

Accepted: 17 March 2021

Published: 19 March 2021

Publisher's Note: MDPI stays neutral with regard to jurisdictional claims in published maps and institutional affiliations.

Copyright: (c) 2021 by the authors. Licensee MDPI, Basel, Switzerland. This article is an open access article distributed under the terms and conditions of the Creative Commons Attribution (CC BY) license (https:/ / creativecommons.org/licenses/by/ $4.0 /)$.

\begin{abstract}
One of the most important problems of the modern world is food wastage. The issue occurs at every stage of the food chain, requiring new sustainable production and processing technologies. The processing of production waste and making it a wholesome ingredient may be a good opportunity to promote more sustainable development. This study analyzes the process of enrichment of model by-product (irregular potatoes cubes) with a functional compound (ascorbic acid) through vacuum impregnation, with two experiments on variants of the process, standard (VI) and ultrasonic-assisted (UVI). The research covers complete processing, including the stage of preserving impregnated products by convective drying. The analysis includes the impregnation efficiency, drying kinetics, and energy consumption, and selected quality parameters of the material, namely color and water activity. Based on the results, ultrasound increased the impregnation efficiency, but the quantitative effect depends on the application period. Ultrasound had a positive effect on the kinetics and energy consumption of convective drying. Ultrasound did not reduce quality. The proposed technology may be useful during the processing of by-products.
\end{abstract}

Keywords: ascorbic acid; acoustic cavitation; functional food

\section{Introduction}

One of the most important problems of the modern world is the enormous amount of food wastage. It is estimated that about 1.3 billion tons of food is lost, which constitutes one-third of total production. This issue concerns food production, processing, distribution, and consumption [1]. Thus, possibilities for more sustainable use of food are sought. Various strategies are proposed. Foley et al. [2] advise both boosting production, especially on underperforming lands, and changes in eating habits-less food resource-intensive diets. Thi et al. [3] point to the need to develop new, sustainable food production and processing technologies, especially in developing countries. The re-use by-products from food processing and re-introducing them in the production cycle [4] is a strategy that is worth considering for the development of more sustainable technologies. Potato processing is a food industry that generates a very large amounts of waste-up to $40 \%$ of the raw material introduced into the technological process is waste $[5,6]$.

Potato (Solanum tuberosum L.) is a very popular vegetable. The tuber is the nutritious part of this plant and its chemical composition depends on the variety, climatic conditions, and cultivating techniques. In addition to energy, high-quality protein, and dietary fiber, potatoes provide significant amounts of several vitamins (including vitamin C) and minerals. Ascorbic acid (vitamin C), is essential for the proper functioning of the human body, and is involved in many biochemical reactions, removes free radicals, affects the body's resistance to infections, and is one of the most important antioxidants. Moreover, vitamin $\mathrm{C}$ has bacteriostatic and bactericidal properties against some microorganisms and lowers the risk of cancer. Unfortunately, the content of ascorbic acid diminishes greatly during 
the storage and processing of fruit and vegetables. Vitamin $\mathrm{C}$ is very sensitive to environmental $\mathrm{pH}$ (alkaline and neutral), oxygen, metal ions, high temperature, and the activity of oxidizing enzymes, under which it decomposes or loses its biological activity. Vitamin C losses during food processing caused, i.e., by thermal treatment can reach 50-90\% $[7,8]$.

One of the most frequent processing directions of potatoes is the production of French fries or chips. In these processes, the final products have to have a specific shape, thus cutting and sorting generate a large number of raw material losses. However, this waste is still of full value. Enriching these by-products with vitamin $C[9,10]$ and reusing them in dried form as a functional ingredient, for example, in instant foods is a promising strategy.

The enriching of such by-products can be carried out by means of vacuum impregnation (VI). This process is based on the replacement of native liquids and gases from the porous structure of food products into a specially prepared solution-impregnant. The mass transport in VI is the result of a mechanically generated pressure gradient. The main aim of vacuum impregnation is to provide or strengthen the health-promoting properties in food products, including specific sensory and physicochemical properties [11].

VI is a two-stage process. In the first, the so-called vacuum stage, the raw material is placed in a solution of the desired compound, then the pressure is reduced and native fluids located in porous space are removed. In the second, the so-called relaxation stage, the pressure is restored to atmospheric conditions and the open pores/capillaries of the material are filled-impregnated-with the solution [12,13]. It is assumed that vacuum impregnation proceeds through the hydrodynamic mechanism (HDM), and simultaneously, due to deformation-relaxation phenomena (DRP), which are well described in the literature $[11,14,15]$.

In the case of some raw materials, mass transfer is difficult due to their structure and/or composition. The main factor influencing the susceptibility to VI is porosity. The lower the porosity, the more difficult the impregnation. Compared to other raw materials, e.g., apples, which have a porosity of about $25 \%$, potatoes have very low porosity, i.e., around $2 \%$ [16]. High starch content and tissue density also significantly affect the susceptibility to the VI process. One of the techniques for intensification of unit operations is the use of ultrasound, which, so far, has been successfully applied in osmotic dehydration [17,18], drying [19], or vacuum impregnation [20,21]. The important factor that decides on the positive effect of ultrasound is the phenomenon of so-called acoustic cavitation. During this process, the bubbles of gas and/or vapor are formed, grow, and, finally, implode in liquid located in the pores of the material being impregnated. As a result of the implosion, the local temperature and pressure increase rapidly (up to thousands ${ }^{\circ} \mathrm{C}$, and hundreds $\mathrm{atm}$ ), which causes further phenomena that intensify the mass transfer (mixing, micro-jets, viscosity drop, etc.). At the same time, the bubbles expand the pores and create new ones, increasing the porosity of the material, and thus the volume available for impregnation liquid $[19,22]$.

As reported by Mashkour et al. [20] impregnation of whole potatoes with $1 \%(w / w)$ solution of iron ions followed by ultrasound pretreatment ( $140 \mathrm{~W}$ and $37 \mathrm{kHz}$ ) contributes to an increase in the amount of iron that remains after cooking, which is a very positive effect. It also was found that above a certain limit value of the acoustic power, an unacceptable leakage of the substance occurs, which is unfavorable for the final product quality. Increased loss of ions may prove that excessively high ultrasound intensity leads to permanent damage of the cellular structure. Thus, it is very important to control the US intensity and operate in a safe range. On the other hand, in the presented work the temperature of the solution was not controlled during the ultrasound action. In a thermally uncontrolled chamber degradation of nutrients or intensification of leakage is quite probable. Thus, tests in thermally controlled conditions could be very useful and would facilitate the assessment of ultrasound impact itself while excluding the effect of temperature.

The semi-products obtained after VI are not microbiologically stable and susceptible to spoilage and decomposition processes. For this reason, they must undergo further processing. One of the most common food preservation processes is drying. During 
drying, the unbound moisture is removed from the material, which reduces the water activity and thus increases the microbiological stability of vegetables and fruit. Drying, like most processing operations, is a thermal process and leads to many unfavorable changes such as shrinkage, color change, biochemical changes, loss of nutrients, vitamins, etc. For this reason, it is very important to determine the nutrient content of the dried product and assess the impact of this unit-operation on the product quality and durability of the introduced VI compound [13,23,24].

Convective drying with hot air (CV or HAD) is one of the most commonly used methods of thermal moisture removal. Unfortunately, this process is very slow and energyconsuming. It is estimated that various drying operations can consume up to $25 \%$ of the total energy used in the industry. However, this number depends on the country and the structure of the economy. Such high energy consumption is a significant problem in countries where energy production is based mainly on fossil fuels (e.g., coal or oil). Firstly, fossil sources are non-renewable, and secondly, such energy production will put a heavy burden on the environment. Legal regulations aimed at reducing the emission of environmentally harmful factors such as greenhouse gases, increase production costs and the market price of products, which affects the purchasing power of consumers. For these reasons, alternative methods of processing and drying are sought to reduce the drying time, maintain (or improve product) quality, and, most importantly, reduce energy consumption $[19,25,26]$.

In the works published so far, the use of ultrasound was primarily aimed at increasing the efficiency of a given process (drying, extraction, freezing, osmotic dehydration, etc.) [17-19]. However, their influence on the vacuum impregnation and energy consumption of subsequent processing was not analyzed in detail. Taking into account that the acoustic cavitation caused by ultrasounds usually causes permanent changes in the structure of the raw material (increase in porosity, decrease in cohesion), it is reasonable to assume that these changes may affect the kinetics and energy consumption in the subsequent processing (e.g., by drying). However, there are no studies confirming such effects.

The research presented in this paper was aimed at determining the possibility of enriching a model by-product with a functional compound through vacuum impregnation (VI). Additionally, the influence of ultrasound-as a recognized factor intensifying the exchange processes - on the efficiency of vacuum impregnation, the kinetics of post-processing (convective drying), and the selected quality parameters of the obtained products were studied. Specific energy consumption in the drying processes was also analyzed to better assess the proposed technology in terms of sustainability and environmental impact.

\section{Materials and Methods}

\subsection{Material}

Potatoes (Solanum tuberosum L.) 'Colomba' were bought at a local market and stored for at least $24 \mathrm{~h}$ under refrigeration at $4{ }^{\circ} \mathrm{C}$. Before processing, the tubers were peeled and then cut into irregular cubes of c.a. $15 \mathrm{~mm}$ using a commercial food preparation machine RG-100 (Hallde, Sweden). During each experiment, irregular potato cubes were used. This form of the raw material can be considered as a model by-product. The mass of a single batch was $400 \mathrm{~g}$.

\subsection{Vacuum Impregnation}

Vacuum impregnation processes were carried out in the IS-PP apparatus (INTERSONIC Sp. z o.o., Olsztyn, Poland), the diagram of which is presented in Figure 1.

The impregnation was carried out in a $5 \%(w / w)$ aqueous solution of analytically pure ascorbic acid (Chempur, Piekary Ślaskie, Poland). During each process, $2 \mathrm{~kg}$ of the solution was used so the ratio of the weight of raw material to the solution was 1:5. The temperature of the solution was measured with the Pt100 sensor (2) and kept constant at c.a. $25{ }^{\circ} \mathrm{C}$ using a water jacket (7). 


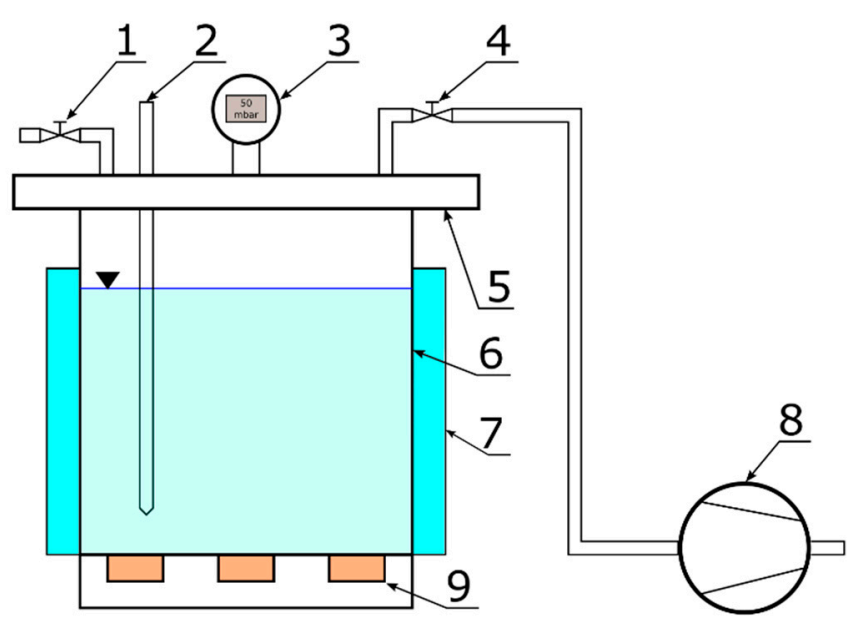

Figure 1. The IS-PP scheme 1,4-valves; 2-PT100 temperature probe; 3-vacuum gauge; 5-lid, 6-vacuum chamber; 7-water jacket; 8-vacuum pump; 9-ultrasonic transducers.

In the course of the research, four different impregnation processes were analyzed. Details of the impregnation processes are presented in Table 1.

Table 1. Description of the impregnation processes.

\begin{tabular}{cccc}
\hline \multirow{2}{*}{ Process } & \multicolumn{2}{c}{ Duration (min) } & \multirow{2}{*}{ Ultrasound } \\
\cline { 2 - 3 } & Vacuum Period & Relaxation Period & - \\
VI & 30 & 30 & during vacuum period \\
UVI1 & 30 & 30 & during relaxation period \\
UVI2 & 30 & 30 & during vacuum and relaxation periods \\
UVI3 & 30 & 30 &
\end{tabular}

VI-vacuum impregnation, UVI-ultrasound-assisted vacuum impregnation.

The prepared potato cubes were placed in the processing chamber (6) (Figure 1) into which the impregnating solution was next poured. The chamber was then closed with a lid (5) and a vacuum was generated over the solution using a vacuum pump (8). The current chamber pressure was measured with a digital pressure gauge (3). When the assumed pressure (50 mbar) was reached, the valve (4) was closed and the vacuum period was started. The raw material and the solution were kept under these conditions for a strictly defined time. After the assumed vacuum time had elapsed, the valve (1) was gradually opened and the chamber was aerated. When the ambient pressure was restored, the cubes were left in the solution for a specified period-the relaxation period.

During the ultrasound-assisted processes (UVI), the ultrasonic waves at a frequency of $35 \mathrm{kHz}$ were generated in the solution by the piezoelectric transducers (9) (Figure 1) attached to the bottom of the chamber. The effective power of ultrasound, measured with the calorimetric method [27], was $40 \mathrm{~W}$. After the assumed time had elapsed, the solution was discharged from the chamber and the batch was drawn onto the screen. Next, the samples were rinsed with tap water to get rid of the excess impregnation solution from the surface and allowed to drain for $3 \mathrm{~min}$. After this time, the batch was divided into two parts and placed in barrier polypropylene bags which were then sealed. One bag was placed in the refrigerator at $4{ }^{\circ} \mathrm{C}$, and the second one in the freezer at $-50{ }^{\circ} \mathrm{C}$.

\subsection{Convective Drying}

In the next stage, the impregnated samples were submitted to convective drying in a laboratory hybrid dryer (PROMIS-TECH, Wrocław, Poland) [28]. For each of the impregnated semi-products, the same parameters of the drying air were used, i.e., air temperature of $70^{\circ} \mathrm{C}$ and air velocity of $4 \mathrm{~m} / \mathrm{s}$. During the drying process, the mass and 
temperature of the material being dried were periodically recorded, which could determine the kinetics of the process.

The kinetics of the drying process was assessed based on moisture content $(M C)$, moisture ratio $(M R)$, drying rate $(D R)$, and drying time $(D T)$. The moisture content of the sample at any time $t$ (different from 0 ) was determined based on the following relationship presented:

$$
M C(t)=\frac{m(t)-m_{s}}{m(t)},
$$

where $m(t)$ is the mass of sample at time $t, m_{s}$ is the mass of dry matter determined through drying in a convective dryer at $105^{\circ} \mathrm{C}$ until constant weight.

Based on the obtained results the relative moisture content $(M R)$ was calculated using the following equation:

$$
M R(t)=\frac{M C(t)-M C_{f}}{M C_{0}-M C_{f}},
$$

where $M C_{0}$ is the initial moisture content and $M C_{f}$ is the final moisture content of the dried material.

The initial moisture content $\left(M C_{0}\right)$ was determined using a moisture analyzer XM120 (precision $0.01 \%$ ) produced by Precisa (Dietikon, Switzerland).

The average drying rate $(D R)$ was calculated based on the following equation:

$$
D R=\frac{\Delta m_{w}}{D T},
$$

where $\Delta m_{w}$ is the mass of moisture (water) evaporated during drying and $D T$ is the total drying time.

Additionally, each process was assessed in terms of energy consumption $(E C)$, which was measured for the whole drying system with the use of a standard electricity meter (precision $0.01 \mathrm{kWh}$ ). Next, the specific energy consumption (SEC) was calculated in accordance with the following equation:

$$
S E C=\frac{3.6 \cdot E C}{\Delta m_{w}},
$$

where 3.6 is the value of $1 \mathrm{kWh}$ calculated to MJ.

All the results of drying parameters analyzed in the studies were compared with the control sample, i.e., raw potatoes dried only convectively without impregnation (CV).

\subsection{Evaluation of the Effectiveness of the Vacum Impregnation}

The effectiveness of vacuum impregnation was assessed based on ascorbic acid content (AAC) in the impregnated semi-products and dried products. The content of ascorbic acid was determined using the HPLC method.

Raw and impregnated material (about $10 \mathrm{~g}$ ) and dried material (about $1 \mathrm{~g}$ ) were homogenized with $25 \mathrm{~mL} \mathrm{1 \%} \mathrm{meta-phosphoric} \mathrm{acid} \mathrm{(Sigma} \mathrm{Aldrich,} \mathrm{Steinheim,} \mathrm{Germany)}$ in an IKA T-25 homogenizer (Staufen, Germany). Next, the samples were shaken for $15 \mathrm{~min}$, after which they were centrifuged for $15 \mathrm{~min}$ in an MPW-351R centrifuge (Warszawa, Poland) at $3800 \times g$. After the centrifugation, the precipitate was again extracted with $10 \mathrm{~mL} \mathrm{1 \%} \mathrm{meta-phosphoric} \mathrm{acid.} \mathrm{The} \mathrm{combined} \mathrm{supernatants} \mathrm{were} \mathrm{filled} \mathrm{to} 50 \mathrm{~mL}$ with $1 \%$ meta-phosphoric acid. $1 \mathrm{~mL}$ of extract and $1 \mathrm{~mL}$ of $5 \%$ dithiothreitol (Sigma Aldrich, Buchs, Switzerland) made up to $10 \mathrm{~mL}$ with $1 \%$ meta-phosphoric acid. The samples were analyzed using the LC Agilent Technologies 1200 Rapid Resolution (Waldbronn, Germany) system equipped with a Poroshell 120, SB-C18 column $(\varnothing 4.6 \times 150 \mathrm{~mm}, 2.7 \mu \mathrm{m})$ (Agilent Technologies, Wilmington, NC, USA). Mobile phases were methanol (Sigma Aldrich, Steinheim, Germany) (phase A) and $0.005 \mathrm{~mol} / \mathrm{L} \mathrm{KH}_{2} \mathrm{PO}_{4}$ solutions (Sigma Aldrich, Tokyo, Japan) (phase B). For the detection of ascorbic acid, a gradient of methanol (solvent A) per $0.005 \mathrm{~mol} / \mathrm{L} \mathrm{KH}_{2} \mathrm{PO}_{4}$ and $\mathrm{pH} 2.6$ (solvent $\mathrm{B}$ ) was used according to the following program: 
linear increment starting with $5 \% \mathrm{~A}$ to $22 \%$ in $6 \mathrm{~min}$ and then returned to the initial conditions within the next $9 \mathrm{~min}$ with a flow rate of $0.7 \mathrm{~mL} / \mathrm{min}$. The eluate was detected with a UV-Vis detector set at $245 \mathrm{~nm}$ [29]. Ascorbic acid was identified by comparing its retention time with that of an ascorbic acid standard (Sigma Aldrich, St. Louis, MO, USA).

\subsection{Measurement of the Selected Product Quality Parameters}

The quality of the semi-products and dry products was judged on the basis of color change $(d E)$ and water activity $\left(a_{w}\right)$. The color of the raw material, impregnated semiproducts, and dried products were measured with the use of a CR400 colorimeter (Konica Minolta, Osaka, Japan) and expressed in the CIELAB color space. Before measurements, 10 potato cubes were ground in the A11 Basic laboratory mill (IKA, Staufen, Germany). The ground sample was immediately placed in a special sample holder and the tristimulus color parameters $\left(L^{*}, a^{*}, b^{*}\right)$ were measured 5 times. This procedure was repeated 5 times, so the total number of color measurement points was 25 . Then the data were averaged and, on their basis, the total color change $(d E)$ was calculated in accordance with the equation:

$$
d E=\sqrt{\left(L_{0}^{*}-L_{s}^{*}\right)^{2}+\left(a_{0}^{*}-a_{s}^{*}\right)^{2}+\left(b_{0}^{*}-b_{s}^{*}\right)^{2}}
$$

where $L^{*}$ indicates lightness, and $a^{*}$ and $b^{*}$ are the chromaticity parameters that indicate color directions: from red to green $\left(a^{*}\right)$ and from yellow to blue $\left(b^{*}\right)$, index 0 denotes the raw material and $s$ denotes the processed sample (impregnated semi-product or dried product).

Water activity $\left(a_{w}\right)$ was measured for fresh and processed potato using the LabMasteraw Standard meter (precision 0.001) produced by Novasina AG (Lachen, Switzerland). The $a_{w}$ analysis was also performed on the ground sample (similar to the color measurement). Paste from raw material or impregnated semi-product and powder from the dried sample were placed in special measuring vessels in a thermostatic chamber of the $a_{w}$ meter. The temperature inside the chamber was fixed at $298 \mathrm{~K}$. The measurement was done automatically and terminated if the change in $a_{w}$ value was smaller than 0.001 for $10 \mathrm{~min}$.

\subsection{Statistical Analysis}

Data shown are mean \pm standard deviation. Additionally, one-way ANOVA and Tukey post-hoc mean comparison were performed. Statistically significant differences at the level of $p \leq 0.05$ are marked with different letters. All calculations were performed using Statistica ver. 12 software produced by StatSoft (StatSoft, Tulsa, Oklahoma, OK, USA).

\section{Results and Discussion}

\subsection{Vacuum Impregnation Effectiveness}

The effectiveness of vacuum impregnation was assessed based on the ascorbic acid content (AAC) determined for semi-products (after vacuum impregnation) and dried products. In Figure 2, the average ascorbic acid content for a particular type of sample is presented.

The standard process of vacuum impregnation (VI) of potato cubes caused an 11-fold increase in ascorbic acid content compared to the raw material (Figure 2). Nine times higher AAC in the impregnated with $10 \%$ ascorbic acid solution of whole potato tuber at $93.3 \mathrm{mbar}$ vacuum pressure during $60 \mathrm{~min}$ and relaxation time lasting $3 \mathrm{~h}$, was found by Hironaka et al. [30]. The application of VI combined with ultrasound during the vacuum (UVI1) or relaxation (UVI2) stage resulted in a $10 \%$ and $33 \%$ increase of AAC, respectively (compared to VI). In turn, the use of ultrasound during both vacuum and relaxation stages (UVI3) caused AAC in tested samples comparable to VI. Application of ultrasound for a longer time, in this case, may cause a reaction, which initiates the formation of free radicals that affect the content of ascorbic acid [31]. A similar effect was found by Nowacka et al. [32] during ultrasound-assisted osmotic dehydration of whole cranberries when using ultrasound for an extended period (60 min). 


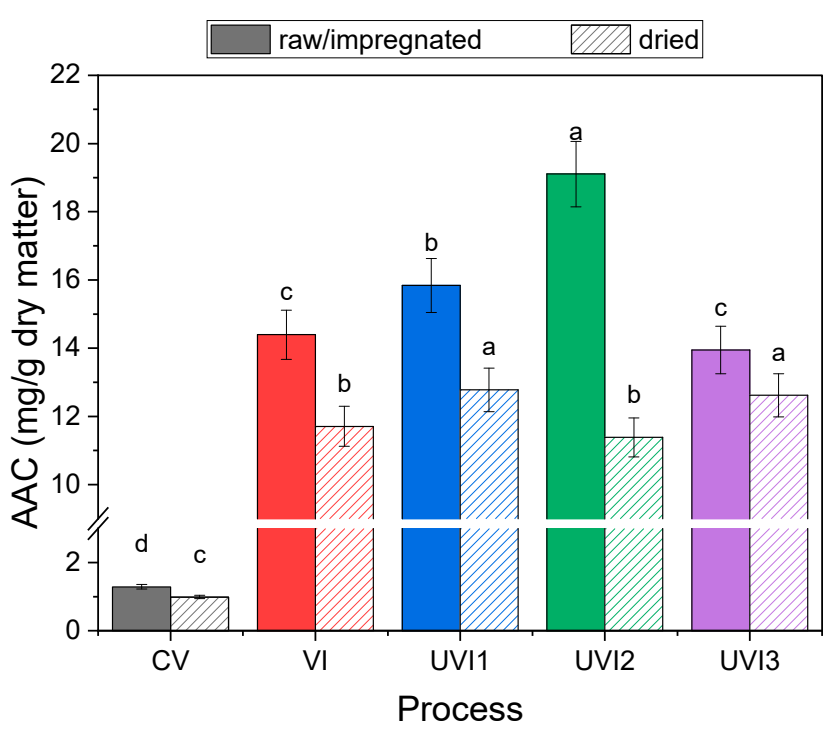

Figure 2. Ascorbic acid content (AAC) of raw, impregnated, and dried samples. Different letters for the same type of bars (filled or hatched) mean a statistically significant difference at the level of $p \leq 0.05$ in accordance to ANOVA and Tukey post-hoc means comparison.

Convective drying of fresh potato cubes resulted in a loss of ascorbic acid amounting to $23 \%$, while, in the VI samples, losses were $19 \%$. In potato cubes subjected to ultrasoundassisted vacuum impregnation, the drying process contributed to decreasing AAC about $19 \%, 40 \%$, and $10 \%$ for UVI1, UVI2, and UVI3, respectively. According to references, the loss of vitamin $\mathrm{C}$ during the drying of potatoes may reach $50 \%$ [33]. The highest decrease of vitamin $C$ was found for samples processed with UVI2. The high AAC may result in a greater susceptibility to the Maillard reaction of potato cubes. Thermal treatment under aerobic conditions caused the conversion of ascorbic acid by dehydroascorbic acid to furan-type compounds, lactones, acids, 3-hydroxy-2-pyrone, furaldehyde, and 5-hydroxymethylfuraldehyde [34]. Hence, if the level of tissue impregnation with ascorbic acid is too high, it may be disadvantageous due to the intensification of changes related to non-enzymatic browning.

\subsection{Convective Drying Kinetics}

The drying kinetics of potatoes were evaluated based on drying curves representing the relative moisture content-moisture ratio $(M R)$ change as a function of time $(t)$. In Figure 3 the plots of $M R$ for individual drying processes are presented.

The curves obtained for the drying of semi-products of impregnation (VI, UVI1-3) were compared within a framework of a single graph to the convective process $(\mathrm{CV})$.

Comparing the curves shown in Figure $3 a$, it can be seen that VI did not influence the kinetics of drying significantly. The use of ultrasound during vacuum impregnation changed the drying kinetics. The course of $M R$ curves for samples impregnated with ultrasonic assistance shows that in the first period of drying the speed of this process was similar to the referential process (CV), while in the second period it was accelerated (Figure $3 \mathrm{~b}-\mathrm{d}$ ). The samples processed with the UVI1 and UVI3 processes had a similar course of $M R$ curves (Figure 3b,d). 
(a)

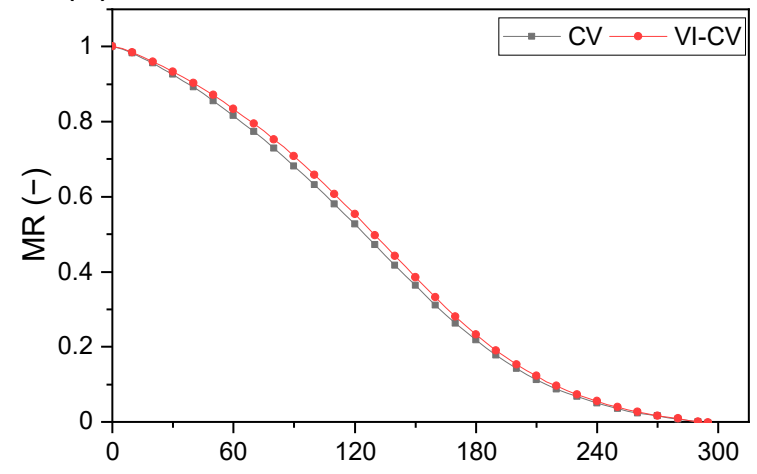

(c)

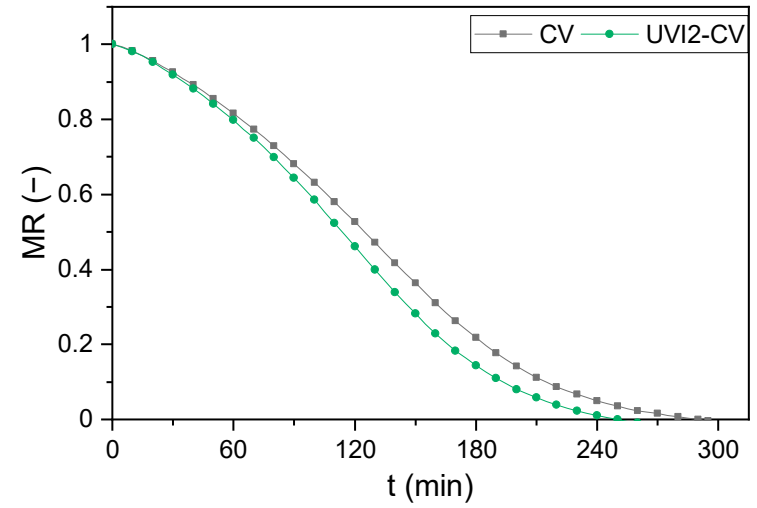

(b)

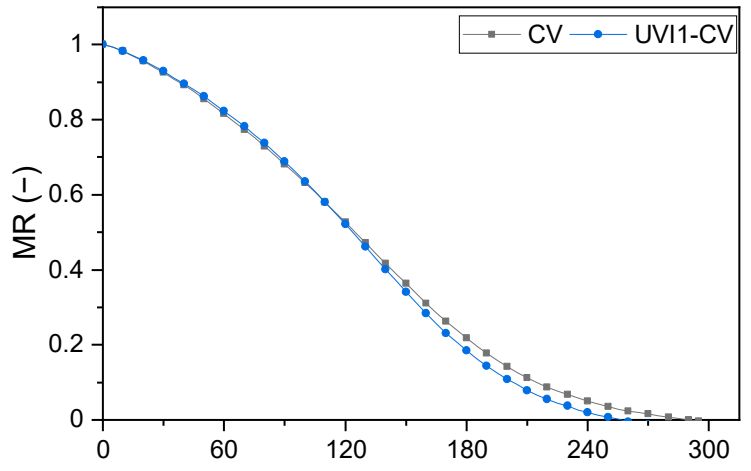

(d)

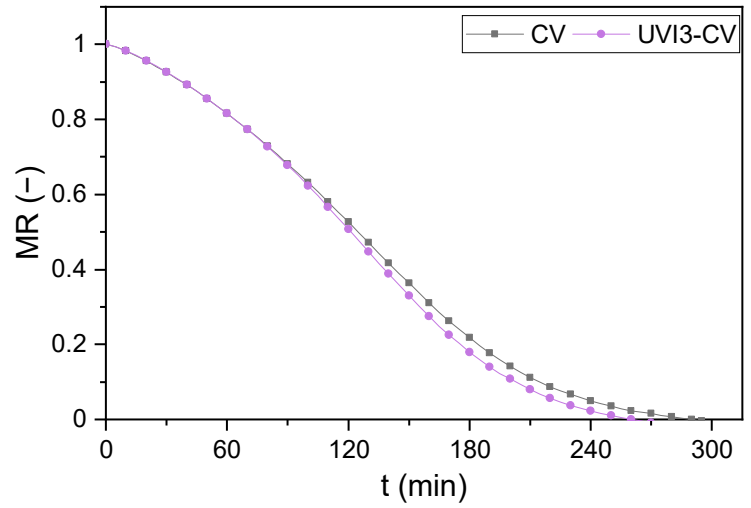

Figure 3. Plots of the moisture ratio (MR) for (a) CV and VI-CV; (b) CV and UVI1-CV; (c) CV and UVI2-CV; (d) CV and UVI3-CV.

Acceleration of the drying process in the second period may indicate structural changes in the processed potato, as the rate of drying in this period is generally controlled by the diffusion of moisture inside the material. The more effective it is, the faster the drying. The complicated structure of biological materials (vegetables and fruit) means that this stage is usually very slow. It is assumed that for most vegetables and fruit, the first drying period-with a constant drying rate, does not occur at all and the process takes place in the second (diffusion-controlled) period-with a falling drying rate. Thus, changes in the internal structure may contribute to an increase in the drying rate. It was stated in the literature that ultrasound induces structural changes, i.e., an increase in pore/capillary diameter, new pores/capillaries formation, and a kind of intercellular channels leading to loosening structure of potato tissue $[21,35]$. This stays in good agreement with the results obtained during this research.

However, it should be emphasized that analysis of the course and slope of the drying curves, only provides information concerning the instantaneous rate of the process. To fully determine the impact of individual impregnation processes on the drying kinetics, the average rate and time of drying for individual processes should be analyzed. In Table 2, the average drying rate $(D R)$, drying time $(D T)$, and specific energy consumption $(S E C)$ are presented. To facilitate the assessment of individual processes, the change in the value of a given parameter in relation to the $\mathrm{CV}$ process was calculated. 
Table 2. Average drying rate $(D R)$, drying time $(D T)$, and specific energy consumption (SEC) for particular VI processes.

\begin{tabular}{ccccccc}
\hline Process & $\begin{array}{c}\text { DR 10 } \\
(\mathbf{g} / \mathbf{m i n})\end{array}$ & $\begin{array}{c}\text { Change } \\
\mathbf{( \% )}\end{array}$ & $\begin{array}{c}\text { DT } \\
(\mathbf{m i n})\end{array}$ & $\begin{array}{c}\text { Change } \\
\mathbf{( \% )}\end{array}$ & $\begin{array}{c}\text { SEC 10 } \\
\mathbf{( M J} / \mathbf{k g})\end{array}$ & $\begin{array}{c}\text { Change } \\
\mathbf{( \% )}\end{array}$ \\
\hline CV & $4.81 \pm 0.24^{\mathrm{c}}$ & - & $290 \pm 14.5^{\mathrm{a}}$ & - & $1.60 \pm 0.08^{\mathrm{c}}$ & - \\
VI-CV & $4.84 \pm 0.15^{\mathrm{c}}$ & $0.70 \%$ & $290 \pm 6.9^{\mathrm{a}}$ & $-0.06 \%$ & $1.57 \pm 0.07^{\mathrm{c}}$ & $-1.15 \%$ \\
UVI1-CV & $5.50 \pm 0.01^{\mathrm{ab}}$ & $14.43 \%$ & $252 \pm 3.4^{\mathrm{b}}$ & $-13.01 \%$ & $1.40 \pm 0.02^{\mathrm{ab}}$ & $-12.84 \%$ \\
UVI2-CV & $5.56 \pm 0.09^{\mathrm{a}}$ & $15.63 \%$ & $247 \pm 3.7^{\mathrm{c}}$ & $-14.71 \%$ & $1.38 \pm 0.01^{\mathrm{b}}$ & $-13.98 \%$ \\
UVI3-CV & $5.44 \pm 0.08^{\mathrm{b}}$ & $13.15 \%$ & $255 \pm 0.2^{\mathrm{b}}$ & $-12.04 \%$ & $1.43 \pm 0.01^{\mathrm{a}}$ & $-10.56 \%$ \\
\hline
\end{tabular}

Mean \pm standard deviation. Letters ${ }^{a},{ }^{b},{ }^{c}$ indicates the statistical significance of the differences between the values in accordance to ANOVA and Tukey post-hoc mean comparison. Values marked with a different letter in a column are statistically different at $p \leq 0.05$.

The obtained values of the average drying rate and drying times are consistent with the results of the analysis of $M R(t)$ curves. The lowest value of $D R$ was recorded for the convective process $(\mathrm{CV})$. Despite a slight decrease in the instantaneous drying rate of VI-CV (Figure 3a), a statistically significant change in $D R$ and reduction of the $D T$ were not observed for this process (Table 2). This may be due to very low porosity and high density of fresh potato. As reported, e.g., by Karathanos et al. [36] the porosity of raw potatoes equals only $2 \%$. Furthermore, during the second stage of VI, i.e., restoration of atmospheric pressure the deformation-relaxation phenomena shrink the capillaries in a potato tissue, to an even smaller volume than before processing. At the same time, the pressure change inside the capillaries causes the material to fill intensively with the impregnating solution $[11,13]$. Thus, the rather low vacuum use in this study, as well as the low porosity of this vegetable, did not have a substantial effect on additional structural changes that could affect the course of the drying kinetics.

Similar results were observed by Pasławska et al. [37] during drying of kale in a fluidized bed. Initial vacuum impregnation of the kale leaves resulted in an increase in the drying rate in the first process period and a decrease in the second one. The authors concluded that a decrease in $D R$ can be attributed to the presence of the impregnating solution, which slowed down the diffusion of water in the deeper layers of the tissue by penetrating them. Moreover, it was found that the dehydration of the kale impregnated in onion juice was larger compared to sodium chloride solution, as onion juice contains more water-soluble compounds.

The use of ultrasound in the VI process caused a significant increase in $D R$ and shortening of $D T$ in relation to the CV and VI-CV samples. In the most favorable case (UVI2-CV), the increase in the average drying speed was about $15.63 \%$, which led to a reduction in drying time by about $14.71 \%$ (Table 2). The smallest changes, in line with the observations of $M R(t)$ curves, were recorded for the UVI3-CV process (an increase in $D R$ by $13.15 \%$ and shortening of DT by $12.04 \%$ ). Taking into account the relatively low ultrasound power $(40 \mathrm{~W})$, the achieved results should be considered very positive. The application of low-power ultrasound was a well-thought-out and justified tactic from the sample integrity point of view. In this way, an effort was made to prevent the potatoes from an excessive change in structure and loss of valuable nutrients.

Another positive effect of using ultrasound during vacuum impregnation was the reduction of energy consumption during drying. A statistically significant increase in $D R$ and reduction in DT observed for the samples pretreated with ultrasound (UVI1-3-CV) caused a $10.56-13.98 \%$ reduction in energy consumed per $1 \mathrm{~kg}$ of evaporated moisture (Table 2, SEC), compared to the convective process (CV). In the case of the VI-CV process, the reduction in $S E C$ was negligible $(1.15 \%)$ which results from a similar value of average $D R$ and $D T$ compared to CV.

The obtained results prove that proper preparation of the raw material (pre-treatment) can lead to a reduction in energy consumption in the main processing operation (in this case, drying). The use of ultrasound during vacuum impregnation allowed not only to 
increase the degree of impregnation with ascorbic acid but also to "loosen" the structure of the raw material (increase in porosity, microchannel formation, and breakdown of starch). As a result, the diffusion of moisture during the drying process was easier, the drying speed was higher and the drying time was shorter, which ultimately contributed to the reduction in the amount of energy needed for drying.

\subsection{Quality Parameters}

\subsubsection{Color}

Figure 4 shows the total color change $(d E)$ for impregnated and dried samples. The $d E$ value presents the change in color parameters of processed samples in relation to the raw material.

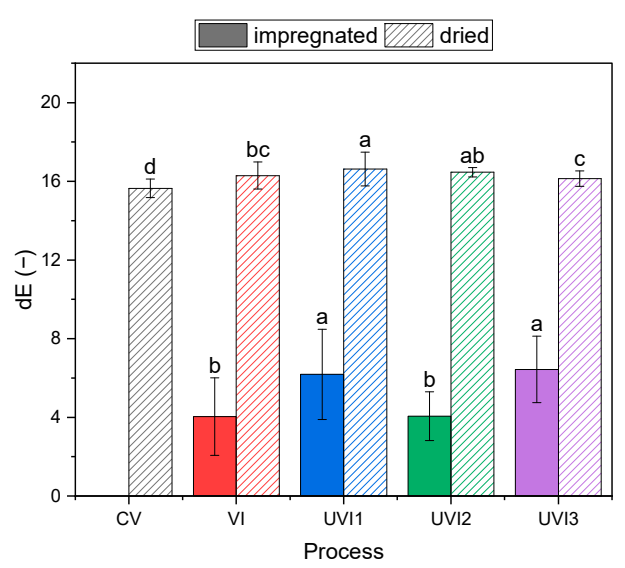

Figure 4. Total color changes $(d E)$ of samples. Different letters for the same type of bars (filled or hatched) mean a statistically significant difference at the level of $p \leq 0.05$ in accordance to ANOVA and Tukey post-hoc means comparison.

Vacuum impregnation of the potato cube, regardless of the method used, resulted in a significant color change in relation to the raw material. The $d E$ values for the impregnated samples ranged from 4 to 6 . The color change in the impregnation step may result from introducing a solution into the plant tissue. As follows for the results (Figure 4-filled bars), the content of ascorbic acid (impregnation solution) in the impregnated potatoes did not visibly influence their color.

The drying process changed the color of the impregnated potatoes remarkably. All dried samples had a value of $d E$ exceeding 15 (Figure 4-hatched bars). The color change during drying results from mainly enzymatic (e.g., peroxidase browning) and non-enzymatic (e.g., Maillard reactions) processes that take place at elevated temperature in an oxygen-rich environment [24]. Convective drying results in greater color changes of samples than vacuum impregnation.

Because the $d E$ usually does not fully reflect the changes in color, a detailed analysis of the tristimulus color parameters $\left(L^{*}, a^{*}\right.$, and $\left.b^{*}\right)$ was performed. Figure 5 shows the average value \pm standard deviation for each parameter separately.

The data presented in the graphs confirm that the color change was influenced by the vacuum impregnation processes as well as drying. In the case of the impregnated samples, the difference in lightness $L^{*}$ (Figure 5a) was statistically significant as compared to raw potato. However, regardless of the impregnation variant the average relative change in $L^{*}$, calculated in relation to the raw material, remained at the level of $1.84 \%$. Thus, it may be assumed that the different variants of vacuum impregnation used in the studies did not affect the lightness of the impregnated samples. A similar tendency was observed in the case of $a^{*}$ and $b^{*}$ parameters. The difference in $b^{*}$ was smaller and indicates a reducing the share of yellow color. Greater and statistically significant changes took place in the case of $a^{*}$. Impregnated semi-products were characterized by a lower value of $a^{*}$ (Figure 5b), which means a growth of the translucency and a color shift towards shades of green. 

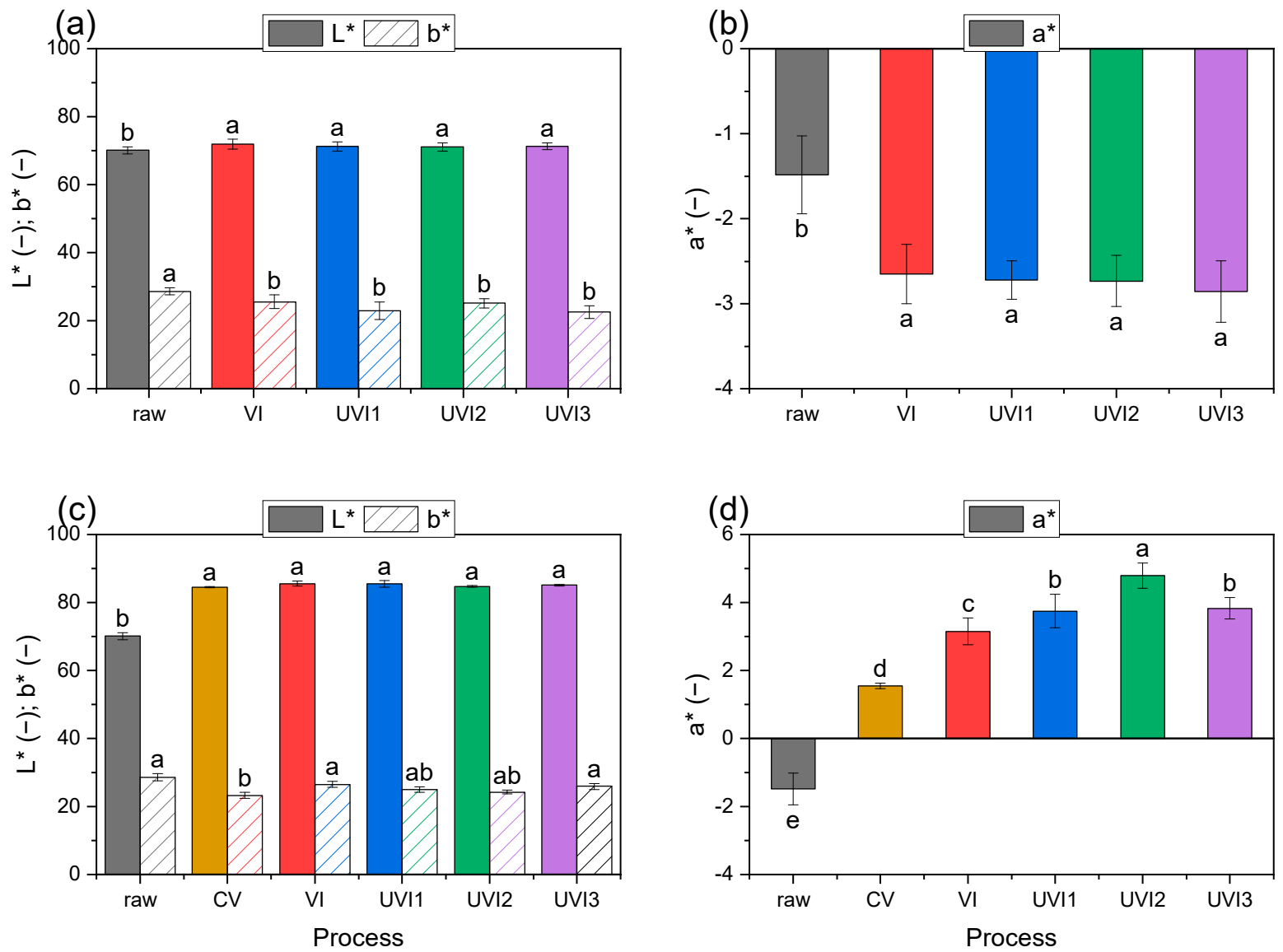

Figure 5. Relative value of tristimulus color parameters of: $(\mathbf{a}, \mathbf{b})$ impregnated; $(\mathbf{c}, \mathbf{d})$ dried samples. Different letters for the same type of bars (filled or hatched) mean a statistically significant difference at the level of $p \leq 0.05$ in accordance to ANOVA and Tukey post-hoc means comparison.

In the case of dried products, the difference in $L^{*}$ was also statistically significant compared to raw potato. The average relative change was $21.31 \%$, which indicates that the dried products were lighter in comparison to raw material (Figure $5 \mathrm{c}$ ). However, no significant differences between the dried samples were found. The differences in $b^{*}$ for dried products were mostly not statistically significant (Figure $5 \mathrm{c}$ ) as compared to raw potato. Similar to impregnated products, for the dry samples the highest differences were observed in $a^{*}$. It was a statistically significant difference compared to raw material. The increase in $a^{*}$ parameter (Figure $5 \mathrm{~d}$ ) indicates a color shift towards the red tone. Moreover, it was found that the value of $a^{*}$ parameter in dry potato samples correlates well with the ascorbic acid content in the impregnated semi-products (compare Figure 2-filled bars and Figure $5 \mathrm{~d}$ ). This may indicate that the change in $a^{*}$ parameter of the dry potatoes was mainly caused by non-enzymatic browning.

\subsubsection{Water Activity}

The next important quality indicator evaluated in these studies was water activity $\left(a_{w}\right)$. This parameter takes a value from 0 (bone-dry material) to 1 (pure water) and depends on the availability of water in the food products. Since water is essential for the growth of most spoilage and decay microorganisms (bacteria, yeasts, molds, etc.). This parameter can determine the microbiological stability and shelf life of food. It is assumed that if the $a_{w}$ is below 0.6 the food is well preserved-stable in terms of decaying processes [38]. The results of water activity for raw material, impregnated, and dried potatoes are shown in Figure 6. 


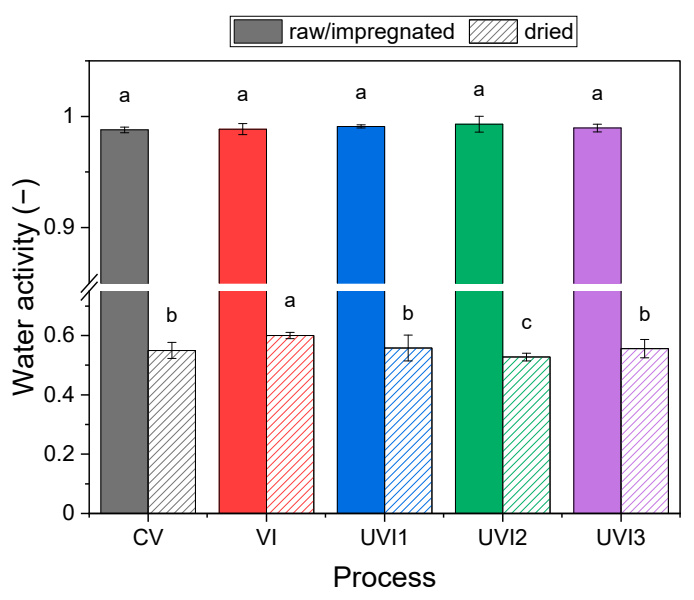

Figure 6. Water activity $\left(a_{w}\right)$ of samples. Different letters for the same type of bars (filled or hatched) mean a statistically significant difference at the level of $p \leq 0.05$ in accordance to ANOVA and Tukey post-hoc means comparison.

As shown in Figure 6, the water activity for fresh and impregnated samples is quantitatively similar, i.e., in the range of $0.988-0.993$. On the one hand, it means that the water contained in the biological material forms a solution of many chemical compounds, and, therefore, its water activity is lower than that of pure water (solvent). On the other hand, it can be stated that the vacuum impregnation did not cause any statistically significant changes in the water activity of the potatoes, and ascorbic acid did not act as a suppressor of water activity.

Taking into account the values for dried samples, it can also be stated that the drying process was successful and, in most cases, the samples had a value of $a_{w}$ below the threshold of 0.6 , which means no microbial proliferation [23]. The only exception is sample VI-CV, where $a_{w}$ exceeds slightly the critical threshold. In this case, the development of osmophilic yeasts and few molds cannot be excluded [39,40]. A high value of water activity may result from the impregnation of the tissue, not only with ascorbic acid but also with water, which penetrates deeper into the tissue and becomes more strongly bonded by gelatinization during drying. In practice, the drying of fruit and vegetables is carried out to the specific values of water activity (in relation to the requirements of the standards). Furthermore, long-lasting drying and thus reduction of $a_{w}$ to very low values may cause a case hardening. A lower $a_{w}$ value for samples subjected to ultrasound-assisted impregnation (UVI1-3-CV) (in comparison to VI-CV samples) may result from structural changes and easier diffusion of moisture inside the material during drying. It is in good agreement with the results of the kinetic parameters $(D R, D T)$.

\section{Conclusions}

The processing of plant materials such as vegetables and fruit is necessary due to their perishability. Processing operations, however, generate significant amounts of waste that increase food losses. On the other hand, the waste generated during production often requires further processing operations (e.g., drying) allowing for its safe disposal or recycling. Such operations increase the consumption of energy, which negatively affects the energy efficiency of the process and natural environment. The results presented in this paper encourage optimism about the application potential of the analyzed process. Thanks to the use of ultrasound-assisted vacuum impregnation, it is possible to obtain products with a high content of impregnating compounds (in this case, ascorbic acid). In this way, it is possible to transform worthless production waste into a valuable product. Furthermore, changes caused by the action of ultrasound may contribute to the improvement of energy efficiency of further processing processes (in this case drying), which is undoubtedly an added value. However, the effective application of this process, both in potato and other 
plant materials requires further research concerning optimization of process parameters and determination of the impact of ultrasound on the varied structure of raw materials.

Author Contributions: Conceptualization, D.M.; methodology, D.M. and E.R.-K.; formal analysis, D.M., J.S., E.R.-K. and R.B.-M.; investigation, D.M. and J.S.; writing-original draft preparation, D.M., J.S., E.R.-K. and R.B.-M.; writing—review and editing, D.M., J.S., E.R.-K. and R.B.-M.; visualization, D.M.; supervision, D.M. All authors have read and agreed to the published version of the manuscript.

Funding: The research was supported by National Science Centre (Poland) in the framework of SONATA project no. 2018/31/D/ST8/00627.

Institutional Review Board Statement: Not applicable.

Informed Consent Statement: Not applicable.

Data Availability Statement: Not applicable.

Conflicts of Interest: The authors declare no conflict of interest. The funders had no role in the design of the study; in the collection, analyses, or interpretation of data; in the writing of the manuscript, or in the decision to publish the results.

\section{References}

1. KC, K.B.; Haque, I.; Legwegoh, A.; Fraser, E. Strategies to Reduce Food Loss in the Global South. Sustainability $2016,8,595$. [CrossRef]

2. Foley, J.A.; Ramankutty, N.; Brauman, K.A.; Cassidy, E.S.; Gerber, J.S.; Johnston, M.; Mueller, N.D.; O'Connell, C.; Ray, D.K.; West, P.C.; et al. Solutions for a cultivated planet. Nature 2011, 478, 337-342. [CrossRef] [PubMed]

3. Thi, N.B.D.; Kumar, G.; Lin, C.-Y. An overview of food waste management in developing countries: Current status and future perspective. J. Environ. Manag. 2015, 157, 220-229. [CrossRef]

4. Bas-Bellver, C.; Barrera, C.; Betoret, N.; Seguí, L. Turning Agri-Food Cooperative Vegetable Residues into Functional Powdered Ingredients for the Food Industry. Sustainability 2020, 12, 1284. [CrossRef]

5. Schieber, A.; Stintzing, F.; Carle, R. By-products of plant food processing as a source of functional compounds-Recent developments. Trends Food Sci. Technol. 2001, 12, 401-413. [CrossRef]

6. Gracia, A.; Gómez, M.I. Food Sustainability and Waste Reduction in Spain: Consumer Preferences for Local, Suboptimal, and/or Unwashed Fresh Food Products. Sustainability 2020, 12, 4148. [CrossRef]

7. Wang, J.; Law, C.L.; Mujumdar, A.S.; Xiao, H.-W. The Degradation Mechanism and Kinetics of Vitamin C in Fruits and Vegetables During Thermal Processing. In Drying Technologies for Foods: Fundamentals and Applications; Nema, P.K., Kaur, B.P., Mujumdar, A.S., Eds.; CRC Press, Taylor \& Francis Group: Boca Raton, FL, USA, 2019; pp. 275-301, ISBN 9781138733084.

8. Zhang, H.; Patel, J.; Bhunia, K.; Al-Ghamdi, S.; Sonar, C.R.; Ross, C.F.; Tang, J.; Sablani, S.S. Color, vitamin C, $\beta$-carotene and sensory quality retention in microwave-assisted thermally sterilized sweet potato puree: Effects of polymeric package gas barrier during storage. Food Packag. Shelf Life 2019, 21, 100324. [CrossRef]

9. Veras, A.O.M.; Béttega, R.; Freire, F.B.; Barrozo, M.A.S.; Freire, J.T. Drying kinetics, structural characteristics and vitamin C retention of dedo-de-moça pepper (Capsicum baccatum) during convective and freeze drying. Braz. J. Chem. Eng. 2012, 29, 741-750. [CrossRef]

10. Weber, P.; Bendich, A.; Schalch, W. Vitamin C and human health-A review of recent data relevant to human requirements. Int. J. Vitam. Nutr. Res. 1996, 66, 19-30. [PubMed]

11. Derossi, A.; De, T.; Severini, C. The Application of Vacuum Impregnation Techniques in Food Industry. In Scientific, Health and Social Aspects of the Food Industry; Valdez, B., Ed.; InTech: London, UK, 2012; ISBN 978-953-307-916-5.

12. Chiralt, A.; Fito, P.; Barat, J.; Andrés, A.; González-Martínez, C.; Escriche, I.; Camacho, M. Use of vacuum impregnation in food salting process. J. Food Eng. 2001, 49, 141-151. [CrossRef]

13. Radziejewska-Kubzdela, E.; Biegańska-Marecik, R.; Kidoń, M. Applicability of vacuum impregnation to modify physico-chemical, sensory and nutritive characteristics of plant origin products-A review. Int. J. Mol. Sci. 2014, 15, 16577-16610. [CrossRef]

14. Fito, P.; Pastor, R. Non-diffusional mechanisms occurring during vacuum osmotic dehydration. J. Food Eng. 1994, 21, 513-519. [CrossRef]

15. Chiralt, A.; Fito, P. Transport Mechanisms in Osmotic Dehydration: The Role of the Structure. Food Sci. Technol. Int. 2003, 9 , 179-186. [CrossRef]

16. Witrowa-Rajchert, D. Study on changes in the plant tissue volume during rehydration. Acta Agroph. $2003,2,867-878$.

17. Kowalski, S.J.; Szadzińska, J. Convective-intermittent drying of cherries preceded by ultrasonic assisted osmotic dehydration. Chem. Eng. Process. Process Intensif. 2014, 82, 65-70. [CrossRef]

18. Zielinska, M.; Markowski, M. Effect of microwave-vacuum, ultrasonication, and freezing on mass transfer kinetics and diffusivity during osmotic dehydration of cranberries. Dry. Technol. 2018, 36, 1158-1169. [CrossRef] 
19. Musielak, G.; Mierzwa, D.; Kroehnke, J. Food drying enhancement by ultrasound-A review. Trends Food Sci. Technol. 2016, 56, 126-141. [CrossRef]

20. Mashkour, M.; Maghsoudlou, Y.; Kashaninejad, M.; Aalami, M. Effect of ultrasound pretreatment on iron fortification of potato using vacuum impregnation. J. Food Process. Preserv. 2018, 42, e13590. [CrossRef]

21. Yilmaz, F.M.; Ersus Bilek, S. Ultrasound-assisted vacuum impregnation on the fortification of fresh-cut apple with calcium and black carrot phenolics. Ultrason. Sonochem. 2018, 48, 509-516. [CrossRef]

22. Awad, T.S.; Moharram, H.A.; Shaltout, O.E.; Asker, D.; Youssef, M.M. Applications of ultrasound in analysis, processing and quality control of food: A review. Food Res. Int. 2012, 48, 410-427. [CrossRef]

23. Labuza, T.P.; Tannenbaum, S.R.; Karel, M. Water content and stability of low-moisture \& intermediate-moisture foods. Food Technol. 1970, 25, 35-42.

24. Maltini, E.; Torreggiani, D.; Venir, E.; Bertolo, G. Water activity and the preservation of plant foods. Food Chem. 2003, 82, 79-86. [CrossRef]

25. Barbosa de Lima, A.G.; Da Silva, J.V.; Pereira, E.M.A.; dos Santos, I.B.; de Lima, W.B. Drying of Bioproducts: Quality and Energy Aspects. In Drying and Energy Technologies; Delgado, J., Barbosa de Lima, A., Gilson, Eds.; Springer International Publishing: Cham, Switzerland, 2016; pp. 1-18, ISBN 978-3-319-19767-8.

26. Abdelaziz, E.A.; Saidur, R.; Mekhilef, S. A review on energy saving strategies in industrial sector. Renew. Sustain. Energy Rev. 2011, 15, 150-168. [CrossRef]

27. Plattes, M.; Köhler, C.; Gallé, T. Disequilibrium calorimetry for determination of ultrasonic power in sonochemistry. MethodsX 2017, 4, 274-278. [CrossRef]

28. Kowalski, S.J.; Pawłowski, A. Intensification of apple drying due to ultrasound enhancement. J. Food Eng. 2015, 156, 1-9. [CrossRef]

29. Kurilich, A.C.; Jeffery, E.H.; Juvik, J.A.; Wallig, M.A.; Klein, B.P. Antioxidant capacity of different broccoli (Brassica oleracea) genotypes using the oxygen radical absorbance capacity (ORAC) assay. J. Agric. Food Chem. 2002, 50, 5053-5057. [CrossRef]

30. Hironaka, K.; Kikuchi, M.; Koaze, H.; Sato, T.; Kojima, M.; Yamamoto, K.; Yasuda, K.; Mori, M.; Tsuda, S. Ascorbic acid enrichment of whole potato tuber by vacuum-impregnation. Food Chem. 2011, 127, 1114-1118. [CrossRef]

31. Tiwari, B.K.; Patras, A.; Brunton, N.; Cullen, P.J.; O'Donnell, C.P. Effect of ultrasound processing on anthocyanins and color of red grape juice. Ultrason. Sonochem. 2010, 17, 598-604. [CrossRef]

32. Nowacka, M.; Fijalkowska, A.; Dadan, M.; Rybak, K.; Wiktor, A.; Witrowa-Rajchert, D. Effect of ultrasound treatment during osmotic dehydration on bioactive compounds of cranberries. Ultrasonics 2018, 83, 18-25. [CrossRef]

33. Witrowa-Rajchert, D.; Radecka-Wierzbicka, M. Wpływ Techniki Suszenia Konwekcyjnego na Wybrane Wyznaczniki Jakości Suszonej Tkanki Roślinnej. Available online: http:/ /yadda.icm.edu.pl/yadda/element/bwmeta1.element.baztech-834dfd78-2b5 6-4b37-a35f-8702db7b43ec (accessed on 19 March 2021).

34. Kaliś, K. Dwukierunkowe działanie witamyny C a degradacja i suplementacja. Postępy Hig. Med. Doświadczalnej 2015, 69, 1239-1244. [CrossRef]

35. Fernandes, F.A.N.; Rodrigues, S. Application of Ultrasound and Ultrasound-Assisted Osmotic Dehydration in Drying of Fruits. Dry. Technol. 2008, 26, 1509-1516. [CrossRef]

36. Karathanos, V.T.; Kanellopoulos, N.K.; Belessiotis, V.G. Development of porous structure during air drying of agricultural plant products. J. Food Eng. 1996, 29, 167-183. [CrossRef]

37. Pasławska, M.; Nawirska-Olszańska, A.; Stępień, B.; Klim, A. The Influence of Vacuum Impregnation on Nutritional Properties of Fluidized Bed Dried Kale (Brassica oleracea L. Var. Acephala) Leaves. Molecules 2018, 23, 2764. [CrossRef]

38. Fontana, A.J. Understanding the importance of water activity in food. Cereal Foods World 2000, 45, 7-10.

39. Beuchat, L.R. Microbial stability as affected by water activity. Cereal Foods World 1981, 26, 345-349.

40. Beuchat, L.R. Influence of Water Activity on Growth, Metabolic Activities and Survival of Yeasts and Molds. J. Food Prot. 1983, 46, 135-141. [CrossRef] 